\title{
Letters
}

Website: bmj.com

Email: letters@bmj.com

\section{Knowledge can flow from developing to developed countries}

EDITOR-I am pleased that this issue of the $B M J$ explores the many aspects of research in developing countries. The first thing that comes to mind on this issue is how developed countries can teach developing countries, but few people realise that the flow of knowledge can sometimes be reversed. Developed countries can learn and benefit from research in developing countries, particularly from research on infectious diseases and alternative treatments.

More international travel has led to a resurgence of infectious diseases and to a rapid spread to developed countries of diseases that used to be exclusive to the developing world. The emergence of HIV infection has warned us about the global threat of new infections, which are more likely to start in developing countries. ${ }^{1}$ Research and surveillance on infectious diseases are most effectively done in areas where the diseases are common. Early communication and attention to this epidemiological information from developing countries can prevent potential global disasters.

The different needs and healthcare settings in developing countries often stimulate new treatment methods, some of which

\section{Advice to authors \\ We prefer to receive all responses electronically, sent either directly to our website or to the editorial office as email or on a disk. Processing your letter will be delayed unless it arrives in an electronic form. \\ We are now posting all direct submissions to our website within 24 hours of receipt and our intention is to post all other electronic submissions there as well. All responses will be eligible for publication in the paper journal. \\ Responses should be under 400 words and relate to articles published in the preceding month. They should include $\leqslant 5$ references, in the Vancouver style, including one to the BMJ article to which they relate. We welcome illustrations. \\ Please supply each author's current appointment and full address, and a phone or fax number or email address for the corresponding author. We ask authors to declare any competing interest. Please send a stamped addressed envelope if you would like to know whether your letter has been accepted or rejected. \\ Letters will be edited and may be shortened. \\ bmj.com \\ letters@bmj.com}

can be more cost effective than established practices in developed countries. Directly observed therapy, short term (DOTS) for tuberculosis was shown to be effective in Africa and Asia in the early 1950s and has been the standard method of treatment in Hong Kong since then. It was only in 1993 that the US Centers for Disease Control recommended it be considered for all patients with tuberculosis. ${ }^{2}$ Earlier adoption of this research evidence might have prevented some of the deaths and multiple drug resistance associated with tuberculosis in many developed countries in recent years.

Traditional medical practices in developing countries can be a treasure box of alternative or complementary treatments for people in developed countries. Research on the effectiveness of acupuncture has made it a standard treatment in many developed countries. Qing hao su, a Chinese herbal medicine, has been proved to be an effective and safe treatment for malaria." Trials of many Chinese herbal medicines for the treatment of HIV infection and cancer are currently under way.

The lack of advanced technology and sophisticated equipment may limit the quality and scope of some research in developing countries, but a lot of knowledge can be acquired through careful observations and innovative ideas, which do not need a lot of money. Mutual exchange is a more satisfying process than one-way transfer of knowledge and resources. Developed countries will get more in return for their investments in research in developing countries if they are more receptive to findings from these countries.

Cindy L K Lam associate professor

Family Medicine Unit, Department of Medicine,

University of Hong Kong 3/F, Ap Lei Chau Clinic,

Hong Kong SAR, China

1 LeDue JW. World Health Organization strategy for emerging infectious diseases. JAMA 1996;275:318-20.

2 Morse DI. Directly observed therapy for tuberculosisspend now or pay later. BMJ 1996;312:719-20.

3 Hesketh T, Zhu WX. Traditional Chinese medicine: one country, two systems. BMJ 1997;315:115-7.

\section{Let's consider ethics of medical practice first}

EDITOR-During the past year I have attended three meetings on the ethics of research sponsored by the World Health Organization, the Harvard School of Public
Health, and the Indian Council of Medica Research. They were all ignored by the media, although the Indian media report daily on the poor state of the health service and unethical medical practices. The recent alleged maltreatment of a central government minister who died in a private hospital in Delhi has caused particular public concern.

That medical research in developing countries is meagre and of generally poor quality is well known, ${ }^{2}$ and it has not improved in the past 20 years. Should one therefore discuss research ethics in developing countries when they barely exist?

In my view the ethics of medical practice is more important. To see how the public can be safeguarded from an inefficient and often corrupt medical system and receive comprehensive health care of a reasonable quality is paramount. Ordinary people have to choose between an underfunded and inefficient public sector with its long queues, dirty hospitals, and rude staff (not infrequently on strike for more pay) and the expensive private sector, perceived as being run by avaricious doctors fleecing patients through overinvestigation and overtreatment. Many patients, understandably, turn to the more accessible and cheaper practitioners of alternative systems of medicine or even to quacks, who regularly prescribe a cocktail of antibiotics, antimalarials, antipyretics, and steroids for fever. Despite this, $80 \%$ of the Indian gross domestic project spent on health care goes to the private sector.

The medical councils, the main regulatory bodies, are generally ineffective, claiming that they do not have the necessary powers. Only one doctor (a well known actor who used his medical status in an advertisement) has been struck off since their inception. Even the Consumer Protection Act, which includes medical practitioners in its ambit, has not successfully curbed unethical medical practices because of the huge delays in its legal process.

In January 2000 the Ministry of Health recognised the growing concern about the absence of standards to measure the quality of health services and that the medical community in India is not accountable in any manner. It proposed setting up a system of monitoring hospitals and doctors in both the public and private sectors. Perhaps the sad and unfortunate death of a young minister will now result in some belated action.

Samiran Nundy gastrointestinal surgeon Sir Ganga Ram Hospital, New Delhi 110060, India snundy@hotmail.com 